\title{
Risk Factors for Overall Complications and Remote Infection After Gastrectomy in Elderly Gastric Cancer Patients
}

\author{
NAOHIKO NAKAMURA, DAISUKE KAIDA, YASUTO TOMITA, TAKASHI MIYATA, \\ TOMOHARU MIYASHITA, HIDETO FUJITA, SHINICHI KINAMI, NOBUHIKO UEDA and HIROYUKI TAKAMURA \\ Department of Surgical Oncology, Kanazawa Medical University Hospital, Ishikawa, Japan
}

\begin{abstract}
Background/Aim: A significant predictive factor for the occurrence of complications after gastrectomy in elderly gastric cancer patients is yet to be determined. We aimed to evaluate the clinical factors associated with overall complications including remote infection after gastrectomy in elderly gastric cancer patients. Patients and Methods: We retrospectively analyzed data of 101 patients aged over 80 years, who underwent curative gastrectomy. We analyzed the clinicopathological factors that were independently associated with the occurrence of overall complications or remote infection by a logistic regression model. Results: The overall complication rate was $24.8 \%$. We identified pneumonia as a remote infection, and the occurrence rate of remote infections was $5.9 \%$. On multivariate analysis, hemoglobin $(<11 \mathrm{~g} / \mathrm{dl})$ and operation time (>240 min) were significantly correlated with the occurrence of overall complications. Regarding the occurrence of remote infection, performing total gastrectomy and a hemoglobin level $<11$ g/dl were identified as significant risk factors. Conclusion: Preoperative anemia and intraoperative factors, including the surgical procedure, could affect the occurrence of postoperative complications in elderly patients.
\end{abstract}

Gastric cancer (GC) is the fifth most common malignancy and the second most common cause of cancer mortality worldwide (1). Incidence of GC peaks in the seventh decade of life (2), and the proportion of elderly patients diagnosed with GC has increased due to the aging of the population (3).

This article is freely accessible online.

Correspondence to: Naohiko Nakamura, MD, Ph.D., Department of Surgical Oncology, Kanazawa Medical University Hospital, 1-1 Daigaku, Uchinada, Kahoku, Ishikawa, 920-0293, Japan. Tel: +81 0762862211, Fax: +81 0762864626, e-mail: n1982422@kuhp.kyotou.ac.jp

Key Words: Gastric cancer, complications, gastrectomy, elderly patients.
In particular, Japan is progressing toward an aging society at an unprecedented rate. In this situation, the probability of performing gastrectomy in elderly GC patients is increasing (4). Although endoscopic resection can be an indication for the curative resection of early GC without lymph node metastasis, the main curative therapeutic strategy for GC still consists of gastrectomy. Regarding the treatment for elderly GC patients, surgeons should carefully decide on the indication for surgery and consider the appropriate strategy that is the less aggressive treatment because elderly patients have a high prevalence of complications and mortality after gastrectomy $(5,6)$.

Due to the fact that surgical techniques and perioperative care skills for GC patients have progressed, recent postoperative prognosis has been improved, even among elderly patients (7). Several studies have confirmed the shortterm safety and long-term benefit of surgical resection for GC in elderly patients $(8,9)$. In a recent study, postoperative mortality in elderly GC patients was reported to be $6.1 \%$, which is lower than that in previous studies (10). However, the risk of complications and mortality associated with surgery in elderly GC patients is still higher than that in younger patients $(11,12)$. Postoperative complications including remote infection, which is defined as an infection out of the surgical site, could lead to a longer hospital stay and rehabilitation delay in elderly patients. Particularly, pneumonia as a remote infection after surgery could greatly affect the postoperative quality of life and prognosis in elderly GC patients. Regardless of the increased opportunity to perform gastrectomy for elderly patients, the risk factors for remote infection including pneumonia in elderly GC patients remain unknown. Since elderly GC patients usually have some comorbidities or sarcopenia conditions that could lead to occurrence of severe postoperative complications, detailed understanding of the risk factors associated with the occurrence of overall complications or remote infections is very essential for surgical management in elderly GC patients.

In this study, we aimed to evaluate clinical factors associated with occurrence of complications after gastrectomy in elderly GC patients. Preoperative 
Table I. Patient characteristics.

\begin{tabular}{lc}
\hline & $\mathrm{n}=101$ \\
\hline Gender (male) & $65(64.4 \%)$ \\
Age & $82(80-95)$ \\
ASA PS ( $\geq 2)$ & $83(82.1 \%)$ \\
Comorbidity $(+)$ & $69(68.3 \%)$ \\
BMI & $21.1(15.9-28.4)$ \\
White blood cell $(/ \mu \mathrm{l})$ & $5,390(2,620-17,720)$ \\
NLR & $2.4(0.7-48.9)$ \\
Hemoglobin $(\mathrm{g} / \mathrm{dl})$ & $11.5(4.4-15.8)$ \\
CRP $(\mathrm{mg} / \mathrm{dl})$ & $0.12(0.02-12.2)$ \\
Total protein $(\mathrm{g} / \mathrm{dl})$ & $6.8(4.2-8.0)$ \\
Albumin $(\mathrm{g} / \mathrm{dl})$ & $3.7(1.5-4.9)$ \\
Cholinesterase $(\mathrm{U} / \mathrm{l})$ & $233(96-544)$ \\
Creatinine $(\mathrm{mg} / \mathrm{dl})$ & $0.90(0.48-5.74)$ \\
CEA (ng/ml) & $3.1(0.5-426.0)$ \\
CA19-9 $(\mathrm{U} / \mathrm{ml})$ & $10.9(0.5-210.0)$ \\
pStage I/II/III/IV1 & $52(51.5 \%) / 23(22.8 \%) / 24(23.8 \%) / 2(2.0 \%)$ \\
Operation & $64(63.4 \%)$ \\
Distal gastrectomy & $13(12.9 \%)$ \\
Total gastrectomy & $16(15.8 \%)$ \\
Proximal gastrectomy & $8(7.9 \%)$ \\
Other & $14(13.9 \%)$ \\
Laparoscopic operation & $8(7.9 \%)$ \\
Lymph node dissection $(\mathrm{D} 2)$ & $212(110-577)$ \\
Operation time (min) & $65(0-1600)$ \\
Bleeding (ml) & $25(24.8 \%)$ \\
Complication $(+)$ & \\
\hline
\end{tabular}

Values are in $\mathrm{n}(\%)$ or medians (range). ASA PS: American Society of Anesthesiologists Physical Status; BMI: body mass index; NLR: neutrophil/lymphocyte ratio; CRP: C-reactive protein; CEA: carcinoembryonic antigen; CA 19-9: carbohydrate antigen 19-9. ${ }^{1}$ The $8^{\text {th }}$ edition of the UICC TNM Staging System for Gastric Cancer (13).

characteristics, pathological findings, and operative outcomes were analyzed to identify the risk factor for not only overall complications, but also remote infections.

\section{Patients and Methods}

We retrospectively analyzed data on 101 patients aged over 80 years, who underwent curative gastrectomy for GC at the Kanazawa Medical University Hospital between January 2009 and December 2019. Clinical data before surgery, such as sex, age, American Society of Anesthesiologists Physical Status (ASA PS) score, comorbidity, and body mass index (BMI), were extracted from our hospital's database. We collected the results of the blood examination before the surgery, including data regarding the white blood cell (WBC) count, the fraction of neutrophil/lymphocyte ratio (NLR) in the WBC differential, hemoglobin level, and serum levels of $\mathrm{C}$-reactive protein (CRP), total protein, albumin, cholinesterase, creatinine, carcinoembryonic antigen (CEA), and carbohydrate antigen 19-9 (CA 19-9). Pathological results were assessed according to the 8th edition of the UICC TNM Staging System for Gastric Cancer (13). Gastrectomy and lymph node dissection were performed according to the 2014 Japanese GC treatment guidelines
Table II. Postoperative complications.

\begin{tabular}{ll}
\hline Overall complications & $\mathrm{n}=25$ \\
\hline Delayed gastric emptying & $8(32 \%)$ \\
Anastomotic leakage & $6(24 \%)$ \\
Pneumonia & $6(24 \%)$ \\
Surgical site infection & $3(12 \%)$ \\
\hline
\end{tabular}

(version 4) (14), and intraoperative outcomes were evaluated. Postoperative complications were assessed on the basis of the Clavien-Dindo classification (15), and $\geq$ grade II complications were included in the analysis. We obtained informed consent from the patients. This study was approved by the Medicine Ethics Committee of Kanazawa Medical University. The research reported in this paper was in compliance with the Helsinki Declaration.

Statistical analysis. Data were expressed as $n(\%)$ or medians (range). Continuous variables were compared using the Student's $t$-test, while categorical variables were compared using the $\chi^{2}$ test. All $p$-Values were two-sided, and differences with a $p$-value of $<0.05$ were considered statistically significant. A logistic regression model was used to identify clinical factors that were independently associated with the occurrence of postoperative complications. Variables that were associated with the occurrence of postoperative complications at $p \leq 0.10$ in the univariate analysis were included in the multivariate analysis. All statistical analyses were performed using JMP software version 8.0 (SAS Institute, Cary, NC, USA).

\section{Results}

The patient characteristics are shown in Table I. The median age of the study population was 82 years, and $66.4 \%$ of patients were males. More than $80 \%$ of patients showed ASA PS $\geq 2$, and $68.3 \%$ had comorbidities such as diabetes mellitus or hypertension that needed treatment by medication. The median levels of serum CEA and CA19-9 were within the normal range. Pathological stage I, II, III, and IV accounted for 51.5, 22.8, 23.8, and 2.0\% of patients, respectively. Regarding surgical outcomes, distal, total, and proximal gastrectomy were performed in 63.4, 12.9, and $15.8 \%$ of patients, respectively, and laparoscopic surgery in $13.9 \%$ of patients. Clavien-Dindo classification $\geq$ grade II complications were observed in 25 (24.8\%) patients. Regarding the details of complications, delayed gastric emptying, anastomotic leakage, pneumonia, and surgical site infection occurred in $8(32 \%), 6(24 \%), 6(24 \%)$, and 3 $(12 \%)$ patients (Table II). All delayed gastric emptying was associated with distal gastrectomy.

In analyzing the correlation between the clinical factors and the occurrence of overall complications (Table III), hemoglobin levels $(p=0.001)$, operation time $(p=0.04)$, serum levels of CRP $(p=0.07)$ and albumin $(p=0.09)$, and ASA PS 
Table III. Univariate and multivariate analyses to identify risk factors for the occurrence of overall complications.

\begin{tabular}{|c|c|c|c|c|}
\hline & \multicolumn{2}{|c|}{ Univariate analysis } & \multicolumn{2}{|c|}{ Multivariate analysi } \\
\hline & Odds ratio & $p$-Value & Odds ratio & $p$-Value \\
\hline Gender (male) & 0.81 & 0.66 & & \\
\hline Age $(>82)$ & 1.08 & 0.86 & & \\
\hline ASA PS $(\geq 2)$ & 3.12 & 0.10 & 3.25 & 0.15 \\
\hline Comorbidity (+) & 0.98 & 0.97 & & \\
\hline BMI $(<20)$ & 0.67 & 0.41 & & \\
\hline $\begin{array}{l}\text { White blood cell } \\
(>9,000 / \mu \mathrm{l})\end{array}$ & 3.22 & 0.27 & & \\
\hline $\operatorname{NLR}(>3)$ & 1.75 & 0.25 & & \\
\hline Hemoglobin $(<11 \mathrm{~g} / \mathrm{dl})$ & 4.66 & 0.001 & 5.00 & 0.002 \\
\hline $\mathrm{CRP}(>1 \mathrm{mg} / \mathrm{dl})$ & 3.11 & 0.07 & 1.91 & 0.40 \\
\hline Total protein $(<6.5 \mathrm{~g} / \mathrm{dl})$ & 1.46 & 0.48 & & \\
\hline Albumin $(<3.5 \mathrm{~g} / \mathrm{dl})$ & 2.31 & 0.09 & 1.40 & 0.59 \\
\hline Cholinesterase $(<200 \mathrm{U} / \mathrm{l})$ & 0.76 & 0.61 & & \\
\hline Creatinine $(>1 \mathrm{mg} / \mathrm{dl})$ & 0.45 & 0.12 & & \\
\hline $\mathrm{CEA}(>5 \mathrm{ng} / \mathrm{ml})$ & 1.33 & 0.59 & & \\
\hline CA19-9 (<37 U/ml) & 0.99 & 0.99 & & \\
\hline pStage III/IV ${ }^{1}$ & 1.13 & 0.82 & & \\
\hline Total gastrectomy & 0.71 & 0.60 & & \\
\hline Laparoscopic operation & 0.80 & 0.72 & & \\
\hline Lymph node dissection (D2) & 1.94 & 0.40 & & \\
\hline Operation time (>240 $\mathrm{min})$ & 3.23 & 0.01 & 3.91 & 0.01 \\
\hline Bleeding (>200 ml) & 1.33 & 0.63 & & \\
\hline
\end{tabular}

ASA PS: American Society of Anesthesiologists Physical Status; BMI: body mass index; NLR: neutrophil/lymphocyte ratio; CRP: C-reactive protein; CEA: carcinoembryonic antigen; CA 19-9: carbohydrate antigen 19-9. ${ }^{1}$ The $8^{\text {th }}$ edition of the UICC TNM Staging System for Gastric Cancer (13). Bold values indicate statistical significance.

( $p=0.10)$ were considered to be significantly correlated with the occurrence of overall complications on univariate analysis. In the multivariate analysis including these factors, hemoglobin $(<11 \mathrm{~g} / \mathrm{dl})$ and operation time (>240 $\mathrm{min})$ were significantly correlated with the occurrence of overall complications ( $p=0.002$ and 0.01 , respectively). In contrast, there was no significant association between the occurrence of overall complications and tumor markers, pathological stage, or surgical procedures.

In the univariate analysis, regarding the correlation between clinical factors and occurrence of pneumonia as a remote infection (Table IV), hemoglobin level $(p=0.02)$, performing total gastrectomy $(p=0.02)$, serum levels of CRP $(p=0.02)$ and albumin $(p=0.03)$, and intraoperative bleeding ( $p=0.04)$ were significantly correlated with the occurrence of pneumonia. There was no significant association between the occurrence of pneumonia and the ASA PS or presence of comorbidity. In multivariate analysis, performing total gastrectomy and a hemoglobin level $<11 \mathrm{~g} / \mathrm{dl}$ were significantly correlated with the occurrence of pneumonia as a remote infection ( $p=0.001$ and $p=0.008$, respectively).
Table IV. Univariate and multivariate analyses to identify risk factors for the occurrence of remote infection.

\begin{tabular}{|c|c|c|c|c|}
\hline & \multicolumn{2}{|c|}{ Univariate analysis } & \multicolumn{2}{|c|}{ Multivariate analysis } \\
\hline & Odds ratio & $p$-Value & Odds ratio & $p$-Value \\
\hline Gender (male) & 2.92 & 0.29 & & \\
\hline Age $(>82)$ & 1.02 & 0.98 & & \\
\hline ASA PS $(\geq 2)$ & 3.25 & 0.12 & & \\
\hline Comorbidity (+) & 0.92 & 0.93 & & \\
\hline BMI $(<20)$ & 1.97 & 0.43 & & \\
\hline $\begin{array}{l}\text { White blood cell } \\
(>9,000 / \mu \mathrm{l})\end{array}$ & 6.13 & 0.20 & & \\
\hline $\operatorname{NLR}(>3)$ & 1.14 & 0.89 & & \\
\hline Hemoglobin $(<11 \mathrm{~g} / \mathrm{dl})$ & 9.84 & 0.02 & 43.08 & 0.008 \\
\hline $\mathrm{CRP}(>1 \mathrm{mg} / \mathrm{dl})$ & 8.50 & 0.02 & 11.67 & 0.05 \\
\hline Total protein $(<6.5 \mathrm{~g} / \mathrm{dl})$ & 1.51 & 0.70 & & \\
\hline Albumin $(<3.5 \mathrm{~g} / \mathrm{dl})$ & 6.26 & 0.03 & 6.02 & 0.15 \\
\hline Cholinesterase $(<200 \mathrm{U} / \mathrm{l})$ & 1.16 & 0.87 & & \\
\hline Creatinine $(>1 \mathrm{mg} / \mathrm{dl})$ & 0.33 & 0.27 & & \\
\hline $\mathrm{CEA}(>5 \mathrm{ng} / \mathrm{ml})$ & 2.09 & 0.50 & & \\
\hline CA19-9 (<37 U/ml) & 2.83 & 0.23 & & \\
\hline pStage III/IV 1 & 3.13 & 0.19 & & \\
\hline Total gastrectomy & 8.50 & 0.02 & 76.51 & 0.001 \\
\hline Laparoscopic operation & 0.81 & 0.17 & & \\
\hline Lymph node dissection (D2) & 2.51 & 0.47 & & \\
\hline Operation time (>240 $\mathrm{min})$ & 1.76 & 0.5 & & \\
\hline Bleeding $(>200 \mathrm{ml})$ & 5.79 & 0.05 & 2.67 & 0.39 \\
\hline
\end{tabular}

ASA PS: American Society of Anesthesiologists Physical Status; BMI: body mass index; NLR: neutrophil/lymphocyte ratio; CRP: C-reactive protein; CEA: carcinoembryonic antigen; CA 19-9: carbohydrate antigen 19-9. ${ }^{1}$ The $8^{\text {th }}$ edition of the UICC TNM Staging System for Gastric Cancer (13). Bold values indicate statistical significance.

\section{Discussion}

Although some studies have been conducted to better adjust the therapeutic strategy for elderly GC patients, treatments for elderly GC patients remain controversial. Elderly patients have more comorbidities than non-elderly patients, and surgery or conventional chemotherapy could be harmful rather than beneficial in some patients. Previous studies have shown that age is a significant predictive factor for postoperative morbidity after GC surgery $(16,17)$. However, a significant predictive factor for the occurrence of postoperative complications in elderly GC patients is yet to be clarified. With the increasing rate of gastrectomy in elderly GC patients, clinical factors that can predict the occurrence of postoperative complications including remote infection are of great interest for making adjustments in the surgical strategy for elderly patients. In this study, we found that preoperative hemoglobin level and operation time were significant predictive factors for overall complications after gastrectomy in elderly GC patients. Of note, a lower hemoglobin level and performing total gastrectomy could 
significantly be associated with the occurrence of postoperative remote infections such as pneumonia.

The overall complication rate after gastrectomy in GC patients over 80 years of age was reported to be $30.8 \%$ in a recent study (18). The present study demonstrated that complications with a Clavien-Dindo classification $\geq$ grade II were observed in $24.8 \%$ of patients, which is consistent with the results of previous reports on elderly GC patients $(19,20)$. In previous studies analyzing elderly GC patients, the elderly group tended to have lower ASA-PS, hemoglobin levels, and serum albumin levels than the control group. In our cohort, more than $80 \%$ of patients exhibited ASA PS $\geq 2$ and the median levels of hemoglobin and albumin were below the normal range. We detected postoperative complications, including delayed gastric emptying, anastomotic leakage, pneumonia, and surgical site infection. Notably, postoperative pneumonia as a remote infection was observed in six patients $(5.9 \%)$. Previous reports showed that postoperative pneumonia occurred in $3-10 \%$ of patients and was the most common complication in elderly patients (18-20). Pneumonia is one of the most important complications after gastrectomy, which could affect the period of hospital stay or the quality of life after discharge in elderly GC patients. Thus, surgeons should understand the risk factors and be careful to prevent the occurrence of pneumonia after gastrectomy.

In this study, preoperative hemoglobin levels were significantly associated with overall complications or remote infection in elderly GC patients. It was previously reported that preoperative lower hemoglobin levels caused postgastrointestinal operative complications such as postoperative fatigue (21). Another previous study demonstrated that the oxygen transferred by hemoglobin was involved in wound healing (22). Based on these results, a lower preoperative hemoglobin level may compromise general tissue oxygenation and hence result in the occurrence of complications. Conversely, preoperative BMI, NLR, or serum albumin levels were reported as a significant risk factor for overall complications after gastrectomy in all generations (23). These preoperative factors did not affect elderly patient morbidity in this study. In contrast, we identified that intraoperative factors were significantly associated with the occurrence of complications. It has been already reported that intraoperative factors are significantly associated with the occurrence of complications after gastrectomy in elderly GC patients $(20,24)$. Interestingly, this study confirmed that, performing total gastrectomy in elderly patients could increase the risk for remote infection. There is no previous report analyzing the risk factors for remote infection in elderly GC patients. Our results suggest that intraoperative factors including the type of gastrectomy have a greater influence on postoperative morbidity and that performing total gastrectomy should be avoided in elderly patients who are at a greater risk for pneumonia. In addition, surgeons should more carefully consider the surgical maneuvers used in elderly GC patients in order to reduce the amount of blood loss during surgery and the operation time, thereby preventing overall complications and remote infection.

This study has certain limitations. It was a retrospective study performed at a single institution, with a small sample size. Thus, to confirm the predictive value of the risk factors for overall complication or remote infection after gastrectomy, further research with a prospective cohort study in multiple institutions is warranted.

\section{Conclusion}

We evaluated the clinical risk factors associated with the occurrence of overall complications or remote infections after gastrectomy in elderly GC patients. Preoperative anemia and intraoperative factors, including the surgical procedure, could affect the occurrence of postoperative complications. Management for anemia before surgery and the choice of a less invasive surgery could be essential for elderly patients to prevent the occurrence of overall complications or remote infections after gastrectomy.

\section{Conflicts of Interest}

The Authors declare no competing interest in connection with this study.

\section{Authors' Contributions}

NN designed the study. NN, DK, and TM performed data acquisition, data analysis, and interpretation. NN prepared the manuscript. YT, TM, HF, SK, NU, and HT revised the manuscript critically. All Authors read and approved the final manuscript.

\section{References}

1 Ferlay J, Soerjomataram I, Dikshit R, Eser S, Mathers C, Rebelo M, Parkin DM, Forman D and Bray F: Cancer incidence and mortality worldwide: sources, methods and major patterns in GLOBOCAN 2012. Int J Cancer 136(5): E359-E386, 2015. PMID: 25220842. DOI: 10.1002/ijc.29210

2 Jung KW, Won YJ, Kong HJ, Oh CM, Lee DH and Lee JS: Cancer statistics in Korea: incidence, mortality, survival, and prevalence in 2011. Cancer Res Treat 46(2): 109-123, 2014. PMID: 24851102. DOI: 10.4143/crt.2014.46.2.109

3 Kamangar F, Dores GM and Anderson WF: Patterns of cancer incidence, mortality, and prevalence across five continents: defining priorities to reduce cancer disparities in different geographic regions of the world. J Clin Oncol 24(14): 21372150, 2006. PMID: 16682732. DOI: 10.1200/JCO.2005.05.2308

4 Cancer Information Service: Cancer statistics in Japan. Available at: http://ganjoho.jp/en/professional/statistics/brochure/index.html [Last accessed on June 8, 2021]

5 Otsuji E, Fujiyama J, Takagi T, Ito T, Kuriu Y, Toma A, Okamoto K, Hagiwara A and Yamagishi H: Results of total 
gastrectomy with extended lymphadenectomy for gastric cancer in elderly patients. J Surg Oncol 91(4): 232-236, 2005. PMID: 16121342. DOI: $10.1002 /$ jso. 20330

6 Wu CW, Lo SS, Shen KH, Hsieh MC, Lui WY and P'eng FK: Surgical mortality, survival, and quality of life after resection for gastric cancer in the elderly. World J Surg 24(4): 465-472, 2000. PMID: 10706921. DOI: 10.1007/s002689910074

7 Kim HH, Han SU, Kim MC, Hyung WJ, Kim W, Lee HJ, Ryu SW, Cho GS, Song KY and Ryu SY: Long-term results of laparoscopic gastrectomy for gastric cancer: a large-scale casecontrol and case-matched Korean multicenter study. J Clin Oncol 32(7): 627-633, 2014. PMID: 24470012. DOI: 10.1200/JCO. 2013.48.8551

8 Takeshita H, Ichikawa D, Komatsu S, Kubota T, Okamoto K, Shiozaki A, Fujiwara H and Otsuji E: Surgical outcomes of gastrectomy for elderly patients with gastric cancer. World J Surg 37(12): 2891-2898, 2013. PMID: 24081528. DOI: 10.1007/ s00268-013-2210-7

9 Seo SH, Hur H, An CW, Yi X, Kim JY, Han SU and Cho YK: Operative risk factors in gastric cancer surgery for elderly patients. J Gastric Cancer 11(2): 116-121, 2011. PMID: 22076212. DOI: 10.5230/jgc.2011.11.2.116

10 Choo JW, Ju Y, Lim H, Youn SH, Soh JS, Park JW, Kang HS, Kim SE, Moon SH, Kim JH, Park CK, Ha HI, Kim MJ, Kim KC and Cho JW: Is it beneficial to perform surgical resection in elderly patients more than 80 years old with advanced gastric cancer? Scand J Gastroenterol 52(10): 1057-1064, 2017. PMID: 28639835. DOI: $10.1080 / 00365521.2017 .1339828$

11 Matsushita I, Hanai H, Kajimura M, Tamakoshi K, Nakajima T, Matsubayashi Y and Kanek E: Should gastric cancer patients more than 80 years of age undergo surgery? Comparison with patients not treated surgically concerning prognosis and quality of life. J Clin Gastroenterol 35(1): 29-34, 2002. PMID: 12080223. DOI: 10.1097/00004836-200207000-00008

12 Park HJ, Ahn JY, Jung HY, Lee JH, Jung KW, Kim DH, Choi $\mathrm{KD}$, Song $\mathrm{HJ}$, Lee GH, Kim JH and Han S: Clinical characteristics and outcomes of gastric cancer patients aged over 80 years: a retrospective case-control study. PLoS One 11(12): e0167615, 2016. PMID: 27942044. DOI: 10.1371/journal. pone. 0167615

13 In H, Solsky I, Palis B, Langdon-Embry M, Ajani J and Sano T: Validation of the 8th Edition of the AJCC TNM Staging System for Gastric Cancer using the National Cancer Database. Ann Surg Oncol 24(12): 3683-3691, 2017. PMID: 28895113. DOI: 10.1245/s10434-017-6078-x

14 Japanese Gastric Cancer Association: Japanese gastric cancer treatment guidelines 2014 (ver. 4). Gastric Cancer 20(1): 1-19, 2017. PMID: 27342689. DOI: 10.1007/s10120-016-0622-4

15 Dindo D, Demartines N and Clavien PA: Classification of surgical complications: a new proposal with evaluation in a cohort of 6336 patients and results of a survey. Ann Surg 240(2): 205-213, 2004. PMID: 15273542. DOI: 10.1097/01.sla. 0000133083.54934.ae
16 Lee KG, Lee HJ, Yang JY, Oh SY, Bard S, Suh YS, Kong SH and Yang HK: Risk factors associated with complication following gastrectomy for gastric cancer: retrospective analysis of prospectively collected data based on the Clavien-Dindo system. J Gastrointest Surg 18(7): 1269-1277, 2014. PMID: 24820136. DOI: $10.1007 / \mathrm{s} 11605-014-2525-1$

17 Persiani R, Antonacci V, Biondi A, Rausei S, La Greca A, Zoccali M, Ciccoritti L and D'Ugo D: Determinants of surgical morbidity in gastric cancer treatment. J Am Coll Surg 207(1): 13-19, 2008. PMID: 18589356. DOI: 10.1016/j.jamcollsurg. 2007.12.050

18 Otowa Y, Okamoto S, Fujinaka R, Arai K, Murata K, Mii Y, Kakinoki K, Oka S and Kuroda D: Feasibility and effectiveness of gastrectomy for elderly gastric cancer patients. In Vivo 33(4): 1307-1311, 2019. PMID: 31280223. DOI: 10.21873/invivo. 11604

19 Hikage M, Tokunaga M, Makuuchi R, Irino T, Tanizawa Y, Bando E, Kawamura T and Terashima M: Surgical outcomes after gastrectomy in very elderly patients with gastric cancer. Surg Today 48(8): 773-782, 2018. PMID: 29536199. DOI: 10.1007/s00595-018-1651-x

20 Wakahara T, Ueno N, Maeda T, Kanemitsu K, Yoshikawa T, Tsuchida $\mathrm{S}$ and Toyokawa A: Impact of gastric cancer surgery in elderly patients. Oncology 94(2): 79-84, 2018. PMID: 29045948. DOI: $10.1159 / 000481404$

21 Yu J, Zhuang CL, Shao SJ, Liu S, Chen WZ, Chen BC, Shen X and $\mathrm{Yu} \mathrm{Z}$ : Risk factors for postoperative fatigue after gastrointestinal surgery. J Surg Res 194(1): 114-119, 2015. PMID: 25450599. DOI: 10.1016/j.jss.2014.09.041

22 Schreml S, Szeimies RM, Prantl L, Karrer S, Landthaler M and Babilas P: Oxygen in acute and chronic wound healing. Br J Dermatol 163(2): 257-268, 2010. PMID: 20394633. DOI: 10.1111/j.1365-2133.2010.09804.x

23 Kanda M: Preoperative predictors of postoperative complications after gastric cancer resection. Surg Today 50(1): 3-11, 2020. PMID: 31535226. DOI: 10.1007/s00595-019-01877-8

24 Takeshita H, Ichikawa D, Komatsu S, Kubota T, Okamoto K, Shiozaki A, Fujiwara $\mathrm{H}$ and Otsuji E: Surgical outcomes of gastrectomy for elderly patients with gastric cancer. World J Surg 37(12): 2891-2898, 2013. PMID: 24081528. DOI: 10.1007/ s00268-013-2210-7
Received May 4, 2021

Revised May 20, 2021

Accepted June 8, 2021 